\title{
Types of soy plant pests and measures against them in the condition of Uzbekistan
}

\author{
M. Zuparov ${ }^{1, *}, M$. Ablazova $^{2}$, and $N$. Irgasheva ${ }^{1}$ \\ ${ }^{1}$ Tashkent State Agrarian University, University str., 2, Tashkent province, Uzbekistan, 100140
}

\begin{abstract}
This paper observed that soybean crops were contaminated with a number of specialized and omnivorous pests in the field, during the storage of grain in warehouses and private households. The study identified 18 species of pests belonging to different families. The main pest of the soybean crop is Dalucho $70 \%$ (at a consumption rate of $5.01 / \mathrm{t}$ ), Cruiser Extra 362 from insecticide seed pesticides against autumn night worms. (When planted with $3.0 \mathrm{l} / \mathrm{t}$, the biological efficiency reaches 85 $90 \%$ and protects the soybean during the entire growing season and prevents pest damage. The main pest of soybeans in field studies against cotton bollworm is the poaching parasite in middle and older cotton According to the results of experiments on the application of nightshade worms in different proportions, the efficiency was $29.8 \%$ on the 3 rd day, $44.5 \%$ on the 7 th day and $75.0 \%$ on the 10 th day when the ratio of freerange and host insects was 1:5. When the parasite was applied at a ratio of $1: 10$, the biological efficiency was $20.7 \%$ on day $3,42.1 \%$ on day 7 and $68.0 \%$ at 10 days. The last variant in the observations was $20.3 \%$ on day 3 when the parasite was used at a ratio of $1: 15,34.4 \%$ at 7 days and $56.1 \%$ at 10 days.
\end{abstract}

\section{Introduction}

Legumes, which are the mainstay of agriculture in the world, are a much-needed food product by the human body because they are rich in essential proteins, fats and carbohydrates [1]. Today, more than $53 \%$ of the world's population consumes soybean oil as a food product. More than 400 products are obtained from the soybean crop; its seeds contain $50 \%$ protein and more than $25 \%$ fat $[1,2]$. An increase in the world's population, in turn, leads to an increase in demand for oilseeds. Today, one of the most pressing issues is to reduce the damage caused by pests that reduce the yield of these crops in order to get an environmentally friendly, high and quality crop [3]. It is the most widely grown oil crop in the world (93 million ha) $[1,3]$.

In addition, in the root rhizosphere of shade there are favorable conditions for the proliferation of antagonistic fungi that kill various diseases, especially vertcellosis and fusarium wilt. In Uzbekistan, a number of studies have been conducted to study the reducing properties of verticellulosis wilt when soybeans are replaced by cotton [4].

\footnotetext{
* Corresponding author: zuparov.m@yandex.com
} 
One of the main factors in obtaining high yields from soybeans is agro-technical measures; soybean cultivation technology (this technology begins with the preparation of land for planting) gives the expected effect when carried out in a timely and quality manner [5]. Another important condition for the expected yield is the selection of varieties that are suitable for soil climatic conditions, resistant to pests and diseases. The length of their growing season should be taken into account when selecting varieties suitable for shady areas $[5,6]$. For example, the vegetation period of very fast ripening varieties is $<80$ days, fast ripening varieties - 80 - 100, medium ripening varieties - $100-110$, late ripening varieties - $130-150$ and very late ripening varieties - $150-170$ days. The advantage of early ripening varieties is that these varieties can also be grown as a secondary crop in all areas where shade can be grown, but early ripening varieties are less productive than medium and late ripening varieties [7].

Soybean crop is mainly destroyed by pests, diseases and weeds. Shade is very resistant to weeds, especially in the first 40-50 days of the growing season. If there are 5 annual weeds per $1 \mathrm{~m}^{2}$, the yield is reduced to $11 \%$, and if 1 perennial weed (root multiplier) is encountered, it is reduced to $74 \mathrm{~kg}$ per hectare [8].

In the main areas where soybeans are grown, early harvest of autumn wheat, corn and other cereals is a good predecessor. Soybeans are mostly planted in areas devoid of wheat and potatoes, and are the best predecessors for these crops [9].

It is not recommended to sow soybeans after legumes and oilseeds in any region, as they have common pests and diseases. It is also not recommended to plant near perennial legumes, as there is a high risk of pests. It is recommended to replant the soybean at least 2 years after it was originally planted or where other oilseeds were planted $[8,10]$.

Like other legumes in the shade, it is advisable to apply bacterial fertilizers (nitragine), which are the best active strains of endogenous bacteria. In this case, the peat preparation of nitragine - rhyzotorphine gives the best effect [11]. The most reliable, simple, effective and inexpensive way to give nitragine is to wet treat the seeds directly before sowing (inoculation). For such purposes, stationary (Mobitox or portable (PO-10)) pesticides are used. The seeds are inoculated in a place where the sun does not shine. After drying, the seeds are packed in bags (30-40 min) and delivered for planting (in accordance with the requirements of protection from sunlight).

Along with all agricultural crops, soybeans are also strongly affected by pests [12]. But within this pest, specialized pests, which are distinguished by their degree of damage, lead to the destruction of many crops in particular.

Soybean is an effective crop for agriculture. There are more than 80 species of pests in the agrocenosis of this crop, which destroy up to $10-60 \%$ of the crop. Pests that damage soybeans live in different phases of the plant (seedlings, leaves and stems, generative organs). These include spider mites, soybeans, soybean thrips, legume saplings, autumn nightshade, cotton and alfalfa nightshades, tuberous long-nosed beetles (coarse-haired, grass and pea long-nosed beetles), beans (beans, peas, etc.) brings However, in the conditions of the republic, the bioecological characteristics of the main pests that cause shade, the area of distribution, the degree of damage, its natural neighbors, the amount of economic damage of pests and measures to combat them are not sufficiently implemented [12-14]. Therefore, the development of an environmentally safe system of shade protection from pests is one of the important tasks today.

According to the literature, crop yields are $60-70 \%$, especially during the growing season of beans, mung beans, peas, and soybeans, and during storage in warehouses and homes by grain bruxus and autumn nightshade, cotton nightshade, spider mite, acacia juice, and other pests. According to the United Nations Food and Agriculture Organization (FAO), 30 to 35 percent of the world's crops are lost each year to pests, diseases, and weeds. Globally, agricultural crops are losing 300 billion USD in crop yields and $40 \%$ of 
crop production is lost. In Russia, the figure is 12-15 billion USD [12, 13, 15]. VN Polevshikova, in the data of VI Sorokina (1965-1967) noted that 23 species of pests cause damage in the moss, and it is important to study the bioecology of these pests [3].

In recent years, researchers have found that polyfag insects that cause damage to soybeans include turnip moth (Agrotis segetum Schiff), cortton bollworm (Heliothis armigera $\mathrm{Hb}$ ), heart and dart moth (Agrotis eclamationis $\mathrm{L}$ ), alfalfa plant bug (Adelphocoris lineolatus), plant bug (Lygus pratensis L), click beetle (Elateridae spp), and simple spider (Tetranychus urticae Koch) were identified [2, 5, 10, 14]. Among the specialized pests of this family of crops, the dominant nodular long-nosed (Sitona) from the grass long-nosed beetle (Sitona sylindricollis Fahr), the coarse-haired long-nosed beetle (Sitona crinitus $H b s t$ ), and the ala pea long-nosed beetle (Sitona lineellus nanskunda), pea aphid (Acyrthosiphon pisim Koch.), alfalfa sap (Aphis craccivora Koch), legume sap (Aphis fabae Scop), and legume thrips (Odontothrips intermedins Uzel) were observed.

According to the results of research on legumes in the fields of agriculture of the Republic, a total of 34 species of pests cause damage to the agrobiocenosis of legumes in the field of pests in legumes. The authors studied 1 species belonging to the genus Arachnoidea (Asariphormes), 4 species belonging to the genus Orthoptera, 13 species belonging to the genus Soleoptera, and 5 species belonging to the genus Homoptera (Homoptera). 3 species belonging to the genus Hemiptera), 2 species belong to the genus Diptera, 5 species belonging to the genus Lepidoptera and 1 species belonging to the genus Thysanoptera. Studies have shown that legume crops have a large number of pest species, but 10 of them cause serious damage. The most common pests of legumes today are spider mites (Tetranychus urticae Koch), turnip moth (Agrotis segetum Schiff), cotton nightshade (Heliothis armigera $\mathrm{Hb}$ ), grass long-nosed beetles (Sitona sylindricollis Fahr), alfalfa sap (Aphis medicaginis craccivora Koch), alfalfa plant bug (Adelphocoris lineolatus Goes), greenhouse alfalfa bug (Trialeurodes vaporariorum Westw), and four-spotted sorrel (Callosebruchus maculates $Z$ ), which destroy crops at a young age and during growth and storage $[2,5,10,14,15]$.

However, in Uzbekistan, we conducted research on the species composition of pests that cause damage to soybeans, the degree of damage and measures to combat their main species.

\section{Materials and methods}

Our research studied the species composition, bioecology, distribution and damage of shade pests in the Tashkent province. In order to protect the young seedlings of soybeans from pests, we sowed the seeds with pesticides before sowing and took measures to control spider mites and cotton bollworm, which are the main pests during the growing season.

In this case, 20 days before sowing of soybean seeds apply insecticides, i.e. soybean seeds with insecticides against the above pests, i.e. Dalucho $70 \%(5.0 \mathrm{~kg} / \mathrm{t})$ and Cruiser Extra $362(3.0 \mathrm{l} / \mathrm{t})$ planted in the purpose of medicine. Seeds were treated at least $15-20$ days before sowing.

The experiment and its efficiency were carried out on the basis of the generally accepted method $[4,6,7]$. To determine the damage of the obtained crop during the growing season and during storage, 5,000 grains from each variant were analyzed.

\section{Results and discussion}

In 2017-2019, it was observed that plants belonging to the legume family, such as moss, beans, soybeans, peas, were damaged in the laboratory and during crop storage, as well as 
during the growing season. Insects that damage shade crops were identified based on the developmental phase of the plants. Long-nosed beetles that damage the roots and young shoots of the shade, fungi of the nightshade, beetles that damage the young shoots $(50 \times 50$ $\mathrm{cm})$ per 50 places per hectare.

10 samples were taken and the topsoil and the number of insects found at a depth of 5 $10 \mathrm{~cm}$ were calculated. Worms taken for sampling and the species were identified after the mushrooms were grown under laboratory conditions.

Entomological handles were used to account for insects during mowing and flowering of plants. At the same time, samples were taken from 4 places by moving two sides 25 times diagonally every 25 meters, and the average number of insects per 100 samples was calculated. A special guide was used to identify the insect species considered.

During the study, it was observed that soybean crops are contaminated with a number of specialized and omnivorous pests in the field, during the storage of grain in warehouses and private homes. These pests are mainly nightshades, spiders, beetles, aphids, beetles, caterpillars, roundworms, beetles, cicadas (cancers), which have been found to cause severe damage to soybean crops. The study identified 18 species of pests belonging to different families (Table 1).

Table 1. Pest species considered in the soybean crop in 2018-2020

(Types of pests identified in Tashkent province)

\begin{tabular}{|c|c|c|}
\hline$\#$ & Types of insects & Appearance \\
\hline 1 & Red spider mite - Tetranychus urticae Koch. & +++ \\
\hline 2 & Moroccan locust - Dociostaurus maroccanus Thumb & +++ \\
\hline 3 & Great green bush-cricket - Tettigonia viridissima L. & + \\
\hline 4 & Bush cricket - Tettigonia caudate Charp. & + \\
\hline 5 & Grass beetles - Setona crinitus Hbst & ++ \\
\hline 6 & Grass long-nosed beetles - Setona cylindricollis Fahr. & + \\
\hline 7 & Pink-eared emperor - Lethrus pygmaecus Ball. & + \\
\hline 8 & Darkling beetle - Opatrum Sabulasum L. & + \\
\hline 9 & Two spotted-dot beetle - Mulovzis bigutkata Gelb. & ++ \\
\hline 10 & Legume beetle - Acanthoscelides altectus Sag & + \\
\hline 11 & Cowpea beetle - Callosebruchus maculates Z & +++ \\
\hline 12 & Pea aphid - Acyrthosiphon onobrychis & +++ \\
\hline 13 & Groundnut aphid - Aphis medicaginis craccivora Koch. & ++ \\
\hline 14 & Plant bugs - Lygus pratensis L. & +++ \\
\hline 15 & Wild moth Euxoa agricola B. & + \\
\hline 16 & Alfalfa plant bug - Adelphocoris lineolatus Goes & ++ \\
\hline 17 & Turnip moth - Agrotis segetum Schiff & +++ \\
\hline 18 & Cotton moth - Heliothis armigera Hb. & ++ \\
\hline
\end{tabular}

Note: most - +++ ... - less

Although the pests that cause damage in the biocenosis of soybean crops are the majority, the following of the most damaging pests were autumn and cotton nightshade belonging to the family Lepidoptera.

Seagulls or butterflies (Lepidoptera) live on insects by damaging several species of legumes. The most important of these are autumn and cotton nights. Autumn nightshade (Agrotis segetum Schiff) is one of the most common pests in irrigated lands. Its worms 
damage the young shoots of several crops belonging to 34 families. In particular, damage to the roots and young seedlings of legumes leads to thinning of seedlings and death of crops at a young age. Cotton nightshade (Heliothis armigera $\mathrm{Hb}$ ) is a dangerous pest of legumes along with many other agricultural crops. Cotton nightshade is widespread in legume crops in areas where peas, soybeans and beans are planted, and they severely damage the grain during the milk ripening period. This insect appears in legumes in mid-June and lays its eggs on young leaves, one by one between the pods. On average, in 4-5 days, the worms hatch from the eggs and feed on the grain by penetrating the young leaves of the plant and then piercing the pods.

Based on the results of preliminary observations, it can be said that the harmful entomofauna of the soybean biocenosis is diverse and the damage they cause is varied. They cause damage at all stages of development of the plant, ie pests that infect the root part of the plant, during the germination period, as well as all the vegetative and generative organs. Of these, spiders are particularly noteworthy since this pest is the most harmful.

It was showed that more than 58 species of pests live in the shade in Uzbekistan. The larvae of other tundra are damaged. Therefore, this part of our study was devoted to studying the effectiveness of insecticidal insecticides against soil-dwelling pests.

In order to protect the young seedlings of soybeans from pests, we conducted research to sow the seeds with pesticides before sowing.

Therefore, soybean seeds were sown with insecticidal pesticides mentioned above, i.e. Dalucho 70\% (5.0 kg/t) and Cruiser Extra 362 (3.0 1/t). Seeds were treated at least $15-20$ days before sowing.

The results showed that in the variant where the Dalucho $70 \%$ fertilizing drug was used at a consumption rate of $5.0 \mathrm{l} / \mathrm{t}$, the germination rate of seeds was $80.4 \%$, while the rate of infestation of young soybean seedlings with autumn tundra did not exceed $8.4 \%$. In this variant, the biological efficiency was $100 \%$ for 21 days and $89.4 \%$ for the following accounting days. The next option, Cruiser Extra 362, was reported to have an efficiency of $88.4 \%$ by 35 days after germination (Figure 1 ).

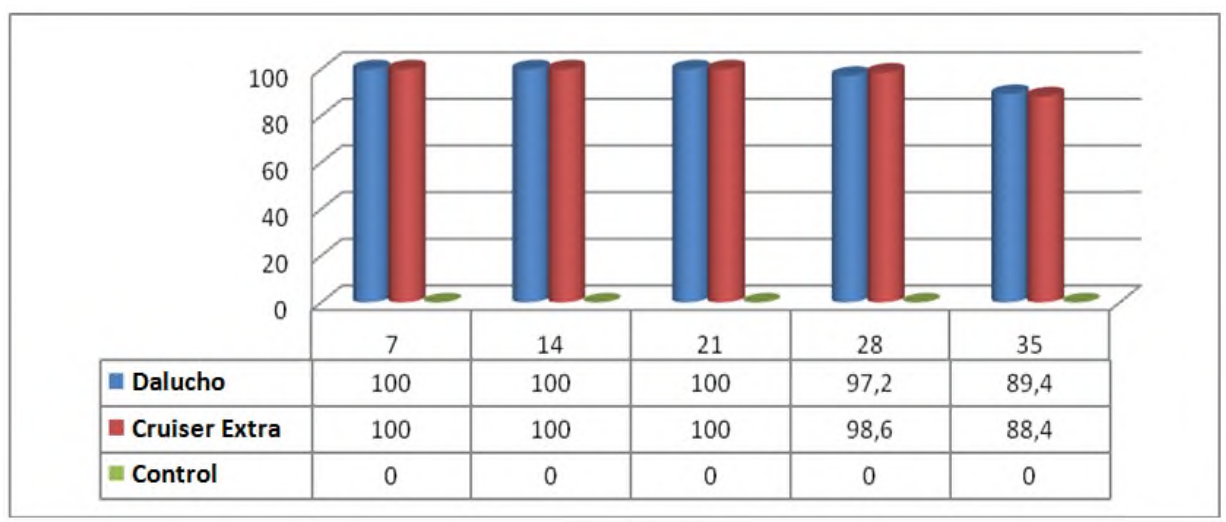

Fig. 1. Biological effectiveness of seeders in root crops against root rot

Summarizing the results of our research, we can say that the seeds of soybean seeds were obtained from insecticidal seed pesticides Dalucho 70\% (at a rate of consumption of $5.01 / \mathrm{t}$ ), Cruiser Extra 362 when planted with drugs at $3.01 / \mathrm{t}$, the biological efficiency reaches $85-90 \%$ and protects the shade throughout the growing season and prevents pest damage.

According to the results of our experiments on the use of poppy parasite in different proportions against middle-aged and adult cotton bollworms, the main pest of the shade 
against cotton bollworm, the efficiency was $29.8 \%$ on day 3 and 7 days at 1:5. Biological efficiency was $44.5 \%$ and $75.0 \%$ on day 10 . When the parasite was applied at a ratio of $1: 10$, the biological efficacy was $20.7 \%$ on day $3,42.1 \%$ on day 7 , and $68.0 \%$ at 10 days. In the observations, when the last variant parasite was applied at a ratio of $1: 15$, the efficiency of the parasites was $20.3 \%$ on day $3,34.4 \%$ on day 7 , and $56.1 \%$ on day 10 (Figure 2 ).

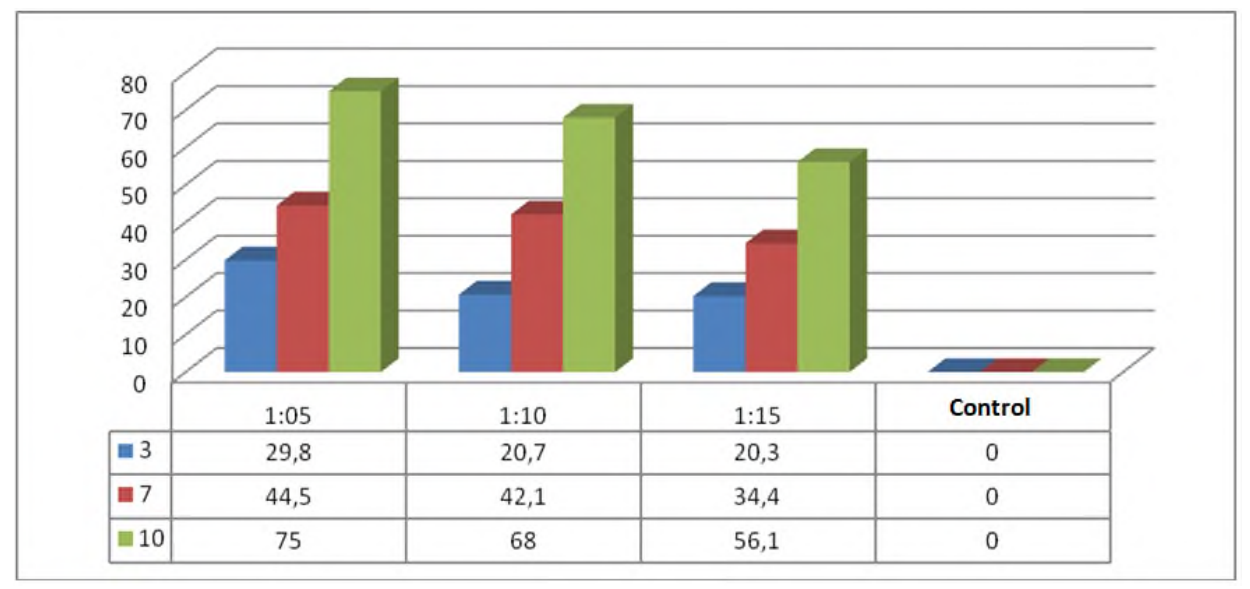

Fig. 2. Biological efficacy of Bracon parasite against cotton bollworm

In the soybean crop, the biological efficiency of 56.1-75.0 is achieved when the poppy parasite against cotton bollworms is applied in the ratios of 1:5-1:10 and 1:15.

\section{Conclusion}

In conclusion, the results of our research show that soybean crops are infested with a number of specialized and omnivorous pests in the field, during the storage of grain in warehouses and private homes. These pests are mainly nightshades, spiders, beetles, aphids, beetles, caterpillars, roundworms, beetles, cicadas (cancers), which have been found to cause severe damage to soybean crops. The study identified 18 species of pests belonging to different families. The main pest of the soybean crop is Dalucho 70\% (at a consumption rate of $5.01 / \mathrm{t}$ ), Cruiser Extra 362 from insecticide seed pesticides against autumn night worms. (When planted with drugs at $3.0 \mathrm{l} / \mathrm{t}$, the biological efficiency reaches $85-90 \%$ and protects the shade throughout the growing season and prevents pest damage.

According to the results of our experiments on the use of poppy parasite in different proportions against middle-aged and adult cotton bollworms, the main pest of the shade against cotton bollworm, the efficiency was $29.8 \%$ on day 3 and 7 days at $1: 5$. Biological efficiency was $44.5 \%$ and $75.0 \%$ on day 10 . When the parasite was applied at a ratio of $1: 10$, the biological efficacy was $20.7 \%$ on day $3,42.1 \%$ on day 7 , and $68.0 \%$ at 10 days. In observations, the latter variant is effective at $20.3 \%$ on day $3,34.4 \%$ on day 7 , and up to $56.1 \%$ on day 10 when the parasite is applied at a ratio of $1: 15$.

\section{References}

1. S. T. Q. Saidganieva, S. N. Q. Yuldasheva, Asian Journal of Multidimensional Research 9(8), 28-30 (2020)

2. M. S. Jaynaqov, Y. Shavkat, American Journal of Plant Sciences 11(8), 1270 (2020) 
3. L. M. Kopaneva, Keys to harmful and beneficial insects and mites of industrial crops 4, 269 (Kolos Press, Saint Petersburg, 2011)

4. Guidelines for testing insecticides, acaricides and molluscicides in crop production 2 , 238 (Kolos Press, Moscow, 2006)

5. S. Khurshida, EurAsian Journal of BioSciences 13(2), 11-21 (2019)

6. R. Shohrukh, International Journal of Human Computing Studies 2(2), 48-50 (2020)

7. V. I. Tanskiy, Biological bases of harmfulness of insects 3, 182 (AgroPromIzdat Press, Moscow, 2008)

8. A. K. Nazarovna, N. F. Bakhromovich, K. A. Alavkhonovich, K. S. S. Ugli, Agricultural Sciences 11(11), 1048 (2020)

9. W. S. Abbot, J. Econ. Entomol. 18(3), 265-267 (2006)

10. V. A. Zakharenko, Bulletin of Plant Protection 1, 22-35 (1999)

11. N. Z. Mamadalieva, D. K. Akramov, E. Ovidi, A. Tiezzi, L. Nahar, S. S. Azimova, S. D. Sarker, Medicines 4(1), 8 (2017)

12. K. Salavatova, D. Annamuratova, Actual Problems of Applied Sciences Journal World 5, 112-117 (2019)

13. D. A. Mirzaeva, N. A. Khujamshukurov, B. O. Soxibov, S. S. Azimov, D. K. Kuchkarova, Int. J. Curr. Microbiol. App. Sci 9(5), 3366-3377 (2020)

14. A. Kholliev, S. Dusmanov, Agro-knowledge 1(29), 36-37 (2014)

15. A. Kholliev, S. Dusmanov, Agro-knowledge 4(32), 45-46 (2014) 